\title{
Assessment on problems associated with artificial insemination service in dairy cattle in Tullo district, West Hararghe, Ethiopia
}

\author{
Riyad Juneyid ${ }^{1}$, Anwar Hassen ${ }^{1}$, Jelalu Kemal ${ }^{1^{*}}$ and Kiros Welay ${ }^{2}$ \\ ${ }^{1}$ Haramaya University, College of Veterinary Medicine, P. O. Box 138, Dire Dawa, Ethiopia. \\ ${ }^{2}$ Haramaya University, School of Animal and Range Land Sciences. \\ *Corresponding author: Haramaya University, College of Veterinary Medicine, P. O. Box 138, \\ Dire Dawa, Ethiopia, Email: jelaluk@gmail.com \\ https: / /dx.doi.org/10.4314/evj.v21i2.5
}

\begin{abstract}
A cross sectional study was conducted from November 2015 to May 2016 with the objective of assessing the problems associated with artificial insemination service in dairy cattle in five selected peasant associations of Tullo district, west Hararghe, Ethiopia. A structured questionnaire was used for 389 dairy cattle owners, 3 artificial insemination technicians and 8 animal health professionals. The result of the study showed that 219 (56.3\%) of the dairy farmers get artificial insemination services regularly and without interruption while $170(43.7 \%)$ do not use this service regularly due to shortage of artificial insemination technicians (18.2\%), discontinuation of service on weekends and holidays (51.2\%) and shortage of inputs (30.6.0\%). Conception failure (34.9\%) was identified by dairy cattle owners as a major problem of AI followed by death of embryo or dystocia (28\%). About $71.1 \%$ of the owners wait for the next oestrus as they are unable to get AI service during heat period while $28.9 \%$ use natural mating if they do not get the service. The questionnaire survey indicated that artificial insemination service faces several constraints and needs improvement for increasing the productivity of dairy cattle in term of genetic improvement in the study area.
\end{abstract}

Keywords: Artificial insemination; Cross breed; Cross sectional; Dairy cattle; Tullo 


\section{Introduction}

In Ethiopia, livestock production accounts for approximately 35 to $49 \%$ of the total agricultural GDP and 16 to $17 \%$ of national foreign currency earnings (Fitaweke Metaferia et al., 2011). The total cattle population for the rural sedentary areas of Ethiopia is estimated at 55.03 million, of which $55.38 \%$ are females, from this 6,675,466 and 10,731,656 were dairy and milking cows, respectively (CSA, 2013). From the total cattle population $98.95 \%$ are local breeds and the remaining are hybrid and exotic breeds. With an average lactation length of 6 months and an average daily milk production of 1.67 litres per cow, the total milk produced during the year 2015/16 was recorded to be 3.06 billion litres (CSA, 2016). This suggests that the total number of both exotic and hybrid female cattle produced through the cross breeding work for many decades in the country is quite insignificant indicating unsuccessful cross breeding work. This again suggests that Ethiopia needs to work hard on improving the work of productive and reproductive performance improvements of cattle through appropriate breeding and related activities (CSA, 2016).

In Ethiopia, the productivity of livestock particularly milk and meat remains low despite the presence of large diverse animal genetic resources due to poor management program, poor genetic potential, inadequate animal health service, location and breed differences and others (Desalegn Gebremedhin, 2005; Tesfaye Ali et al., 2013). Selection of the most promising breeds and cross breeding of local breeds with highly productive exotic cattle has been considered a practical solution to improve the low productivity of local cattle (Bekele Tadesse, 2004).

Artificial insemination (AI), a process by which sperm is collected from the male, processed, stored, and artificially introduced into the female reproductive tract for the purpose of conception (Webb, 2003), has become one of the most important techniques ever devised for the genetic improvement of farm animals. This practice has been widely used for breeding dairy cattle as the most valuable management practice available to the cattle producer and has made bulls of high genetic merit available to all (Webb, 2003; Bearden et al., 2004).

In Ethiopia, AI technology for cattle has been introduced at the farm level over 35 years ago as a means for genetic improvement of cattle (Emeru Zewdie et $a l .$, 2006). The National Artificial Insemination Centre (NAIC) was established 
in 1984 to coordinate the overall AI operation at national level (Desalegn Gebremedhin, 2005). The efficiency of AI service in the country, however, has remained at a very low level due to low accessibility of infrastructure, managerial (such as methods of husbandry, feeding, estrus detection, semen handling and transition cow management), and financial constraints, as well as poor heat detection, improper timing of insemination and death of embryo (Yosef Shiferaw et al., 2003; Tesfaye Ali et al., 2015).

Cattle breeding in Ethiopia are mostly uncontrolled making genetic improvement difficult and an appropriate bull selection criteria have not yet been established, applied and controlled (Azage Tegegn et al., 1995). Reproductive problems related to cross breed dairy cows under farmers' conditions are also vast (Bekele Tadesse, 2005; Alemayehu Lemma and Solomon Kebede 2011). It is obvious that the AI service in the country has not been successful to improve reproductive performance of dairy industry (Desalegn Gebremedhin, 2005). According to some previous studies, it has been found that AI service is weak and even declining due to inconsistent service in the smallholder livestock production systems of the country in general (Ababu Dekeba et al., 2006). The problem is more aggravated by lack of recording scheme, wrong selection procedures, and poor management of AI bulls associated with poor motivations and skills of inseminators (Desalegn Gebremedhin, 2005). In the study area, study of AI related constraints has not yet been done and not well known. The objective of this research was to assess and identify major problems associated with the AI service in the study area.

\section{Materials and Methods}

\section{Study area description}

The current study was conducted from November 2015 to May 2016 in five selected peasant associations (PA's) (Odda, Midheyidu, Kira-kufis, Rakata-fura and Tarkanfata) of Tullo district (Figure 1). All the study areas were purposively selected because these areas are the ones where an AI service is exercised. Tullo district is located in the West Hararghe zone of Oromia regional state. The district is located $371 \mathrm{~km}$ east of the capital city, Addis Ababa and $45 \mathrm{~km}$ from Chiro, zonal town. The rainfall is bimodal with short rainy season from March to May and long rainy season from June to September, followed by dry season from October to February. The district has daily mean temperature ranging from $18^{\circ} \mathrm{C}$ to $26^{\circ} \mathrm{C}$ and mean annual rain fall ranging from $550 \mathrm{~mm}$ 
to $800 \mathrm{~mm}$. The agro ecological zones of the district are highland (dega) $40 \%$, medium high land (weyna dega) $57 \%$ and kola $3 \%$. The district has an altitude ranging from 1500 meters to 2500 meters above sea level and the relative humidity ranges between $22 \%-65 \%$. The district has 33 PA's and three towns with total human population of 14,648 . The livestock populations of the district are 125,915 cattle, 37,973 goats, 13,177 sheep, 171,499 poultry, 5,905 donkeys, 338 horses and 274 mules (CSA, 2013).

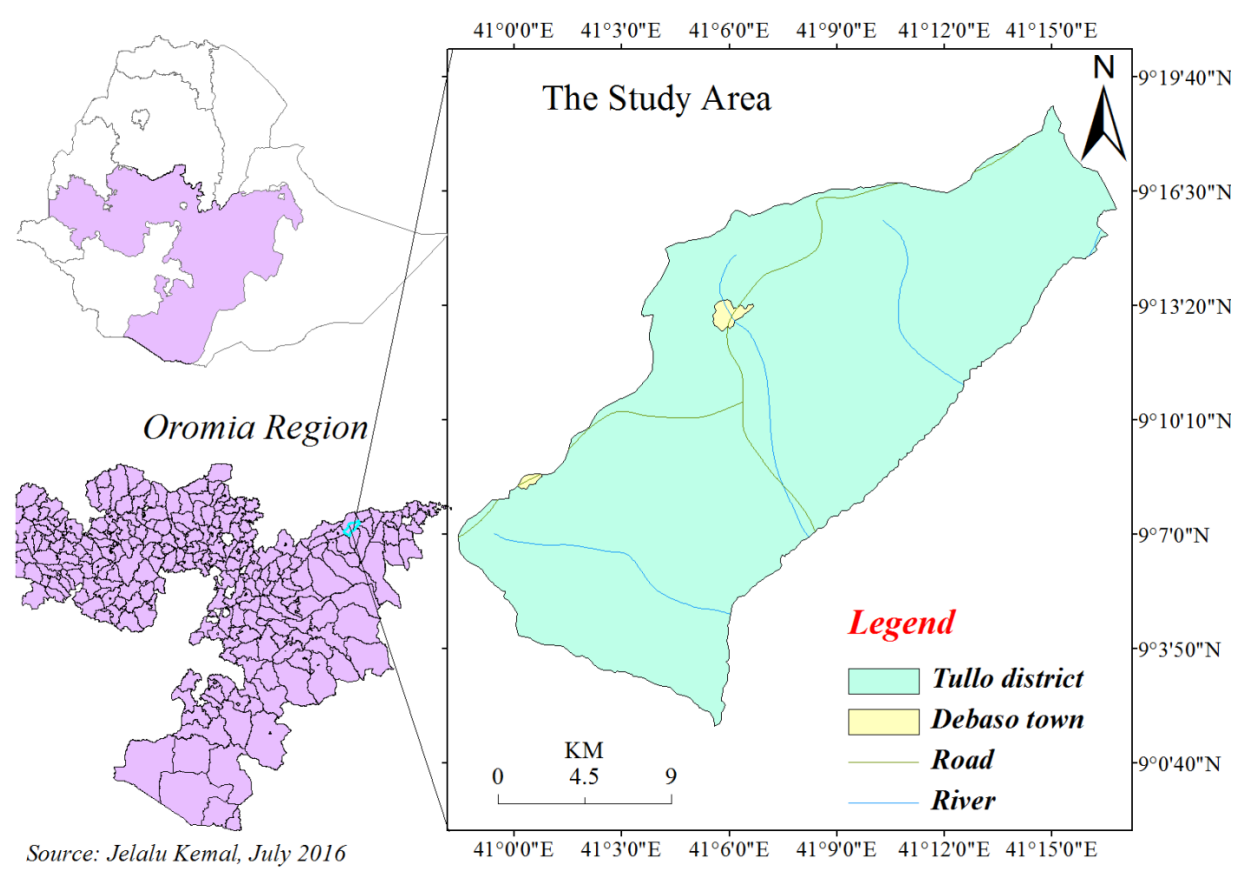

Figure 1. Diagrammatic representation of Tullo district, Oromia, Ethiopia.

\section{Study population}

In this study, dairy cattle owners, artificial insemination technicians (AITs), and animal health professionals in the five selected PA's were represented in the study population. In the rural areas, mainly local Zebu breeds are found grazing on communal land under traditional extensive animal husbandry system while cross breed cows (ZebuxHolstein) were housed and fed with cut and carry system. Cattle production using improved breeds (Holstein) is a common practice in urban and peri-urban (Debaso) areas. Crop residues (Maize, Sorghum) are also fed to the dairy cows in the urban/peri-urban areas. Some dairy 
owners occasionally provide additional straw and Noug Cake. The study on smallholder dairy farms comprised herd size of small farms (1-10 animals) and medium farms (11-20 animals). AI is performed using semen obtained from improved breed (four Holstein Friesian, one Jersey and one cross breed $(\mathrm{ZxH})$ bulls collected and distributed by the National Artificial Insemination Centre located at Kaliti. The age of the cows served by AI ranged between three and ten years. AITs provide both stationed (in nearby veterinary clinic and animal health post) and mobile service delivery by using motor bike that cover up to $30 \mathrm{Km}$ radius around the vet clinic.

\section{Study design and sampling}

A cross-sectional type of study using questionnaire survey was carried out from November 2015 to May 2016 in the five selected PA's dairy cattle owners engaged on smallholder dairy farms, AITs and animal health professionals. Data were recorded about the status of AI service in different PA's such as availability of AI service during weekends and holidays, access of inputs and AITs, knowledge of dairy cattle owners of the different signs of oestrus, AI service problems identified by dairy cattle owners, and owners satisfaction with AI services. The sample size was determined based on the expected prevalence of $50 \%$ and absolute desired precision of $5 \%$ at confidence level of $95 \%$ according to the formula provided by Thrusfield (2005).

This is calculated by using the formula:

$$
\mathrm{n}=\frac{196^{2} \times p_{\exp }\left(1-p_{\exp }\right)}{d^{2}}
$$

Where, $\mathrm{n}=$ required sample size, $\mathrm{P}_{\exp }=$ expected prevalence, $\mathrm{d}^{2}=$ desired absolute precision (5\%). Based on this formula, the total numbers of respondents to be included in the questionnaire survey were 384 . Thus, 389 systematically selected dairy cattle owners, 8 animal health professionals and 3 artificial insemination technicians were included from five PAs in the survey.

\section{Data collection}

Structured questionnaires were prepared to collect data on the status of AI services delivered in the district such as methods of delivery, consistency of service delivery, weekend service provision, and daily accessibility of inseminators and constraints associated with the service from dairy cattle owners' 
perspective, AI technicians and animal health professionals, and identification of signs of oestrus by dairy owners to report cows to be inseminated. In the questionnaire survey, all the 400 respondents (389 dairy cattle owners, 3 artificial insemination technicians and 8 animal health professionals) were briefed about the objective of the study before presenting the actual questionnaire.

\section{Data management and analysis}

The data collected using questionnaire were entered, scored in Ms excel worksheet and coded. The data were entered to SPSS version 16.0 statistical packages for windows and analysis were done. The data was summarized using descriptive statistics analysis such as percentages and Chi-square test to analyse and compare status of AI service in different PA's of the respondents, the level of the knowledge of dairy cattle owners of the different signs of oestrus for AI service and AI service problems. Statistically significant association between variables was considered to exist if the p-value is less than 0.05 .

\section{Results}

Out of 389 dairy cattle owners, $219(56.3 \%)$ receive AI service regularly and without interruption, while 170 (43.7\%) of the respondents could not get the AI service regularly. Out of these 170 owners, $87(51.2 \%)$ did not get services due to discontinuation of service on weekends and holidays, $31(18.2 \%)$ of them due to shortage of AITs and $52(30.6 \%)$ of them due to scarcity of inputs (Table 1).

Table 1. Status of AI service in different PA's of Tullo district.

\begin{tabular}{|c|c|c|c|c|c|}
\hline \multirow[t]{2}{*}{ PA's } & \multirow[t]{2}{*}{$\begin{array}{l}\text { No. of } \\
\text { respondents }\end{array}$} & \multirow{2}{*}{$\begin{array}{l}\text { Receive } \\
\text { AI service } \\
\text { regularly } \\
\text { \& without } \\
\text { interruption } \\
(n=219)\end{array}$} & \multicolumn{3}{|c|}{$\begin{array}{l}\text { Could not get the AI service regularly } \\
(n=170) \text { due to }\end{array}$} \\
\hline & & & $\begin{array}{l}\text { Lack of AI } \\
\text { service during } \\
\text { weekends \& } \\
\text { holidays (\%) } \\
(\mathrm{n}=87)\end{array}$ & $\begin{array}{l}\text { Shortage } \\
\text { of AITs } \\
(\%)(n=31)\end{array}$ & $\begin{array}{l}\text { Shortage of } \\
\text { inputs }(\%) \\
(n=52)\end{array}$ \\
\hline Rakatafura & 84 & $49(58.3)$ & $13(16.7)$ & $5(16.1)$ & 9 (17.3) \\
\hline Odda & 86 & $47(54.7)$ & $15(17.2)$ & $3(9.7)$ & $11(21.2)$ \\
\hline Kirakufis & 81 & $57(66.7)$ & $19(21.8)$ & 7 (22.6) & $6(11.5)$ \\
\hline Midheyidu & 73 & $35(47.9)$ & $24(27.6)$ & $6(19.4)$ & $9(17.3)$ \\
\hline Tarkanfata & 65 & $31(47.7)$ & 18 (20.7) & $10(32.3)$ & $17(32.7)$ \\
\hline Total & 389 & 219 (56.3\%) & $87(51.2)$ & $31(18.2)$ & $52(30.6)$ \\
\hline $\mathrm{X}^{2}$ & & & 11.08 & 24.85 & 27.72 \\
\hline $\mathrm{P}$-value & & & 0.029 & 0.014 & 0.010 \\
\hline
\end{tabular}


The assessment of the knowledge of owners about oestrus signs indicate that majority of the dairy cattle owners do not know one or more signs of oestrus in order to report cows to be inseminated. There was no statistically significant difference ( $>>0.05)$ among the study areas (Table 2).

Table 2. Proportion of dairy cattle owners that have knowledge about specific oestrus signs

\begin{tabular}{|c|c|c|c|c|c|c|}
\hline \multirow[b]{2}{*}{$\begin{array}{l}\text { Signs of } \\
\text { Oestrus }\end{array}$} & \multicolumn{6}{|c|}{ PA's } \\
\hline & $\begin{array}{l}\text { Rakatafura } \\
(\%)(n=84)\end{array}$ & $\begin{array}{l}\text { Odda }(\%) \\
(n=86)\end{array}$ & $\begin{array}{l}\text { Kirakufis } \\
(\%) \\
(n=81)\end{array}$ & $\begin{array}{l}\text { Midheyidu } \\
(\%)(n=73)\end{array}$ & $\begin{array}{l}\text { Tarkanfata } \\
(\%)(n=65)\end{array}$ & Total \\
\hline $\begin{array}{l}\text { Mount other } \\
\text { cows }\end{array}$ & $36(42.8)$ & $38(44.2)$ & $30(37.0)$ & $30(41.1)$ & $27(41.5)$ & $161(41.4)$ \\
\hline Bellowing & $13(15.5)$ & $15(17.4)$ & $25(30.9)$ & $15(20.5)$ & $12(18.5)$ & $80(20.6)$ \\
\hline $\begin{array}{l}\text { Vulval } \\
\text { discharge }\end{array}$ & $10(11.9)$ & $12(13.9)$ & $8(9.9)$ & $10(13.7)$ & $9(13.8)$ & 49 (12.6) \\
\hline Inappetance & $11(13.1)$ & $6(6.9)$ & $7(8.6)$ & $7(9.6)$ & $6(9.2)$ & $37(9.5)$ \\
\hline Restlessness & $14(16.7)$ & $15(17.4)$ & $11(13.6)$ & $11(15.1)$ & 11 (16.9) & $62(15.9)$ \\
\hline Total & 84 & 86 & 81 & 73 & 65 & 389 \\
\hline
\end{tabular}

In relation to problems that occur after the use of AI service, the cattle owners identified conception failure and dystocia or death of embryo as common problems. Among the different PA's higher conception failure was reported in Rakatafura (44\%) and lower in Tarkanfata (13.8\%) (Table 3).

Table 3. Major AI service problems identified by dairy cattle owners in the study area.

\begin{tabular}{|c|c|c|c|c|c|c|}
\hline \multirow{2}{*}{$\begin{array}{l}\text { Problems of } \\
\text { AI services }\end{array}$} & \multicolumn{6}{|c|}{ PA's } \\
\hline & $\begin{array}{l}\text { Rakatafura } \\
(\%)(n=84)\end{array}$ & $\begin{array}{l}\text { Odda } \\
(\%) \\
(n=86)\end{array}$ & $\begin{array}{l}\text { Kirakufis } \\
(\%) \\
(n=81)\end{array}$ & $\begin{array}{l}\text { Midheyidu } \\
(\%)(n=73)\end{array}$ & $\begin{array}{l}\text { Tarkanfata } \\
(\%)(n=65)\end{array}$ & Total \\
\hline $\begin{array}{l}\text { Conception } \\
\text { failure }\end{array}$ & $37(44.0)$ & 34 (39.5) & 31 (38.3) & $25(34.2)$ & $9(13.8)$ & 136 (34.9) \\
\hline $\begin{array}{l}\text { Unavailability } \\
\text { of AITs }\end{array}$ & $16(19.0)$ & $25(29.1)$ & $1(1.2)$ & $11(15.1)$ & $8(12.3)$ & $61(15.7)$ \\
\hline $\begin{array}{l}\text { Death/ } \\
\text { Dystocia }\end{array}$ & $23(27.4)$ & $19(22.1)$ & $25(30.9)$ & $21(28.8)$ & $21(32.3)$ & $109(28.0)$ \\
\hline $\begin{array}{l}\text { Conception } \\
\text { failure }\end{array}$ & $8(9.5)$ & $8(9.3)$ & 24 (29.6) & $16(21.9)$ & 27 (41.5) & 83 (21.3) \\
\hline Total & 84 & 86 & 81 & 73 & 65 & 389 \\
\hline
\end{tabular}


The perception of AI beneficiaries on the time of insemination was assessed and found out that 184 (47.3\%) of the owners request AI service for their cows in the morning if the cow showed heat in the afternoon of the previous day but, the rest 205 (52.7\%) of the dairy cattle owners inseminate their cows at the wrong time mainly having been too late after onset of oestrus. The result showed that $262(67.4 \%)$ dairy cattle owners used AI service repeatedly while 127 (32.6\%) used natural mating. There was no statistically significant difference among the different PA's ( $>>0.05)$. In the current study, from 389 dairy cattle owners $217(55.8 \%)$ were not satisfied by artificial insemination service the rest $172(44.2 \%)$ were satisfied by artificial insemination service. There was statistically significant difference among PA's $(\mathrm{p}=0.007)$ (Table 4).

Table 4. Dairy cattle owners' satisfaction assessment in the area with the overall AI services.

\begin{tabular}{lcccccc}
\hline \multirow{2}{*}{ Satisfaction } & \multicolumn{5}{c}{ PA's } & \\
\cline { 2 - 6 } & $\begin{array}{l}\text { Rakatafura } \\
\mathbf{( \% )}(\mathbf{n = 8 4 )}\end{array}$ & $\begin{array}{l}\text { Odda (\%) } \\
(\mathbf{n = 8 6 )}\end{array}$ & $\begin{array}{l}\text { Kirakufis } \\
\mathbf{( \% )}(\mathbf{n}=\mathbf{8 1})\end{array}$ & $\begin{array}{l}\text { Midheyidu } \\
\mathbf{( \% )}(\mathbf{n = 7 3 )}\end{array}$ & $\begin{array}{l}\text { Tarkanfata } \\
\mathbf{( \% )}(\mathbf{n = 6 5 )}\end{array}$ & Total \\
\hline Satisfied & $38(45.2)$ & $33(38.4)$ & $50(61.7)$ & $27(37)$ & $24(36.9)$ & $172(44.2)$ \\
Not satisfied & $46(54.8)$ & $53(61.6)$ & $31(38.3)$ & $46(63)$ & $41(61.3)$ & $217(55.8)$ \\
Total No & $84(100)$ & $86(100)$ & $81(100)$ & $73(100)$ & $65(100)$ & $389(100)$ \\
\hline
\end{tabular}

$\mathrm{X}^{2}=14.246 ; \mathrm{p}=0.007$

There are only three AITs for the 33 PAs and the results of the questionnaire survey revealed that 2 of them evaluated the quality of training they received as good while one of the technicians evaluated as very good. Two of them responded that they have never received on-job skill training and incentives at all. Only one of the AIT gives service on the weekend and holidays on personal agreements. Two of the AITs complained that material inputs including liquid nitrogen is not readily available while the other technician disagreed. One of them said that he believes that National Artificial Insemination Centre (NAIC) is doing its responsibilities properly. Two of the AI technicians revealed that they do not get necessary supports by the respective district and regional bureaus of agriculture to perform their duties appropriately. Similarly, two of them said that AI service delivery is not consistent in their respective areas.

All of the AITs provide both stationed and mobile service delivery by using motor bike and two of them cover a maximum of $20 \mathrm{Km}$ and the other technician cover 20-30 Km which is convenient for the service they deliver. The average numbers of cows being covered by AITs ranged from 1-10 per day. However, 
all of them thought that the number of services varied between seasons. All of them described they have no other job which affects their work. The most obvious heat sign that have practical importance used by AITs is mucus discharge from the vulva, followed by reddening and swelling of the vulva. All of them said that they would not perform the insemination if the cow did not show any signs of heat. Two of the AITs revealed that cows that come to heat early in the morning should be inseminated on the same day afternoon. Two of the AITs revealed that they are not satisfied and neither are happy with their jobs as AITs because of the very little attention given to it by all responsible bodies.

From 8 animal health professionals, 7 (87.5\%) said that, there are no functionally effective responsible bodies at zonal and district levels to coordinate the AI services. Moreover, 5 (62.5 \%) of the respondents indicate that there are problems associated with the AI service with regards to properly carrying out responsibilities by the NAIC and the zone/ district agriculture offices. Three (37.5\%) of the professionals stated that there are no appropriate collaborations and communications between the NAIC, zonal, district and other dairy owners. In relation to this, 2 (25\%) of them did not have any information whether the semen obtained from NAIC have the desired quality or not.

Animal health professionals pointed out the constraints that inadequate budget allocation, deficiency and irregular supply of inputs in the area (liquid nitrogen and semen), shortage of AITs, insufficient AI centre, lack of managerial and technical support and poor awareness creation in dairy farmers about the AI service are the major problems associated with AI services in the study area. Similarly, out of the 8 animal health professionals, 7 (87.5\%) of them confirmed that lack of breeding policy, less nitrogen plant centre, lack of attention and incentives to AI technicians, limitation of inputs and facilities, shortage of AITs and poor collaboration of government bodies with NGO's, community and other concerned bodies are the major problems associated with AI.

\section{Discussion}

The result of the study indicates that more than half of the farmers get regular AI service which is higher than earlier studies by Alazar Woretaw et al. (2015), Desalegn Gebremedhin (2008) and Ephrem Tadesse (2011) who reported $34.2 \%, 27.7 \%$ and $30.2 \%$ at Debretabour, Kaliti and Wolaita Sodo towns respectively. This could be attributed to farmers very little knowledge about oestrus and due to the lack of awareness of farmers about the importance of

Ethiop. Vet. J., 2017, 21 (2), 62-74 
cross breeding. The difference in shortage of inputs among PAs might be due to the difference in accessibility and the distance to cover from the AI centre (Hirna town) to the PA's and the number of dairy cattle that are found in the PA's.

As per the findings of this study, Nuraddis Ibrahim et al (2014) also reported the most common constraints of AI service as AITs (31.3\%) and conception failure (18\%). They also reported other constraints of AI service like insufficient AI centres, poor awareness among dairy farmers about the AI service, lack of managerial and technical support, and shortage of inputs. Bekele Tadesse (2005) ranked constraints of AI service from highest to lowest as feed source, perception of AI users about AI, poor oestrous detection systems, efficiency of AITs, distance from local AI centre, input for AI activity, price for AI and disease. Haileyesus Abate (2006) ranked major AI service constraints as effi- ciency of AITs, heat detection systems, unavailability of AI service, perception of AI users about AI, distance from local AI centre and price for AI in order of their importance. The difference in the response of dairy cattle owners in the different study areas may be attributed to the difference in their location from NAIC or local AI centre, awareness of farmers about the use of AI, knowledge of oestrus signs and proper heat detection, proper time of insemination, knowl-edge and skill of AITs about handling of semen during transportation, skill and time of insemination.

The current study revealed that $71.1 \%$ of dairy cattle owners postpone time of insemination for the next cycle of insemination when the service is not avail- able (due to different factors such as holidays, weekends and unavailability of AITs) while $28.9 \%$ of them use natural mating if they do not get the service. This result in postponing the time of AI is comparable with the reports $(61.8 \%$ and $38.2 \%)$ by Alazar Woretaw et al (2015), (62.5\% and 37.5\%) by Nurad-dis Ibrahim et al (2014) and (55.79\% and $44.21 \%)$ by Zerihun Baheriw et al (2013). This may indicate absence of bull for natural mating. Dairy cattle own-ers who use natural mating may have low awareness about the use of AI or may have kept bull for breeding because of inaccessibility of AI service.

The current study showed that out of the total 389 dairy cattle owners, 217 (55.8\%) were not satisfied in different ways in the use of AI service as a result of absence of service during weekends and holidays, shortage of AITs, shortage of inputs. On the other hand, $172(44.2 \%)$ were satisfied in AI service in the area. Desalegn Gebremedhin (2008) also reported similar level of dissatisfac- 
tion in his study area. This indicate that, although most of the dairy cattle owners have awareness and want to use AI service for improvement of the genetic potential of their animals, they are unable to get the service mainly due to shortage of AITs and AI inputs.

\section{Conclusion}

Discontinuation of service on weekends and holidays, shortage AITs, shortage of input, insufficiency of managerial and technical support are among constraints associated with AI service in the study site. Similarly, dairy cattle owners, AITs and animal health professional are not satisfied in the AI service delivery system. There should be training for improvement of the knowledge and skills of the existing AITs for enhancing skills. Continuous awareness creation and extension activities should be provided to dairy cattle owners on the detection of heat, time of artificial insemination, possible problems associated with breeding, other health problems and overall management of their animals. Further detailed study should be conducted taking into consideration this baseline information to point out the problems for the improvement of AI service in the area

\section{Acknowledgements}

We would like to address our appreciation to all participants during the assessment particularly artificial insemination technicians, veterinarians and dairy cattle owners of Tullo district for their commitment and cooperation throughout the study time. We highly acknowledge Haramaya University College of Veterinary Medicine for hosting the work.

\section{References}

Ali, T., Lemma, A. and Yilma, T. 2013. Reproductive performance of dairy cows under artificial insemination in south and northwest part of Ethiopia. Livest. Res. Rural. Dev., 25, Article \#191. http://www.lrrd.org/lrrd25/11/ali25191.htm

Bearden, H. J., Fuquary, J. W., Willard, S. T., 2004. Applied Animal Reproduction. $6^{\text {th }}$ edition. Mississippi State University. Pearson, Prentice Hall. Upper Saddle River, New Jersey 07458. Pp. 155-233.

Bekele, T. 2004. Calf Sex Ratios in Artificially Inseminated and Natural Mated Female Cross bred Dairy Herd. In: proceedings of the $13^{\text {th }}$ annual conference of the Ethiopian Society of Animal Production, Addis Ababa, Ethiopia, Pp. 225-230. 
Central Statistical Agency (CSA), Agricultural Sample Survey. Report on Livestock and Livestock Characteristics (Private Peasant Holdings), Vol. 1, Central Statistical Agency (CSA), Addis Ababa, Ethiopia, 2015.

Central Statistical Agency (CSA). 2013. Report on Livestock and livestock characteristics (Private peasant holdings). Statistical Bulletin 570. Addis Ababa: Federal Democratic Republic of Ethiopia; Volume II.

Dekeba, A., Ayalew, W., Hedge, P. B. and Taddese, Z. 2006. Performance of the Abernossa Ranch in the production of Ethiopian Boran x Holstein cross bred dairy heifers in Ethiopia. Ethiop. J. Anim. Prod., 6, 33-53.

Ephrem, T. 2011. Study on challenges of AI in selected woredas of Wolaita zone. DVM Thesis, Jimma University, Jimma, Ethiopia.

Gebremedhin, D. 2005. All in one: A Practical Guide To Dairy Farming. Agri-Service Ethiopia Printing Unit, Addis Ababa. Pp. 15-21.

Gebremedhin, D. 2008. Assessment of problems/constraints associated with artificial insemination service in Ethiopia. MSc Thesis, Addis Ababa University, Ethiopia.

Haileyesus, A. 2006. Evaluation of artificial insemination service efficiency and reproductive performance of f1 Friesian crosses in North Gondar Zone, MSc Thesis, Haramaya University, Ethiopia.

Ibrahim, N., Hailu, R. and Mohammed, A. 2014. Assessment of problems associated with artificial insemination service in selected districts of Jimma Zone, Jimma, Ethiopia. J. Reprod. Infertil., 5(2), 37-44.

Lemma, A. and Kebede, S. 2011. The effect of mating system and herd size on reproductive performance of dairy cows in market oriented urban dairy farms in and around Addis Ababa. Revue. Méd.Vét., 162(11), 526-530

Lobago, F. 2007. Reproductive and Lactation Performance of Dairy Cattle in the Oromia Central Highlands of Ethiopia with Special Emphasis. Doctoral thesis, Swedish University of Agricultural Sciences, Uppsala.

Metaferia F, Cherenet T, Gelan A, Abnet F, Tesfay A, Ali JA, Gulilat W. A. 2011. Review to Improve Estimation of Livestock Contribution to the National GDP. Ministry of Finance and Economic Development and Ministry of Agriculture. Ethiopia: Addia Ababa.

Shiferaw, Y., Tenhagen, B. A., Bekana, M. and Kasa, T. 2003. Reproductive performance of cross bred dairy cows in different production systems in the central highlands of Ethiopia. Trop. Anim. Hlth. Prod., 25, 551-561. 
Tadesse, B. 2008. Calf sex ratios in artificially inseminated and natural mated female cross breed dairy herd. In: Proceedings of the $13^{\text {th }}$ annual Conference of Ethiopian Society of Animal Production. Addis Ababa, Ethiopia, Pp. 227.

Tegegn, A., Kassa, T. and Mukassa-Mugerwa, E. 1995. Aspects of bull production with emphasis on cattle in Ethiopia. П. Sperm production capacity and semen characteristics. In: Proceeding of the Third National Conference of Ethiopian Society of Animal production. Pp. 83-99.

Tesfaye, A., Alemayehu, L., Tefera, Y. and Endris, A. 2015. Factors affecting the reproductive performance of smallholder dairy cows in two regions of Ethiopia. Livestock Res. Rur. Dev., 27 (3). Article number 46: http://www.lrrd.org/lrrd27/3test27046. html..

Thrusfield, M. 2005. Survey in Veterinary Epidemiology. $2^{\text {nd }}$ editions. USA: Blackwell Science, Limited, Cambridge.

Webb, D. W. 2003. Artificial Insemination in Cattle. University of Florida, Gainesville. IFAS Extension, DS 58. Pp. 1-4.

Woretaw, A., Bemrew, A., Anmaw, S. and Saddam, M. 2015. Assessment of the problems associated with Artificial Insemination service on dairy cattle in Debretabour town, Ethiopia. J. Reprod. Infertil. 6(2), 48-55.

Zerihun, B., Malede, B. and Tewodros, F. 2013. Assessment on Problems Associated with Artificial Insemination Services in West Gojjam Zone, Ethiopia. Adva. Biol. Res. 7(2), 59-66.

Zewdie, E., Mussa, A., Melese, G. M., HaileMariam, D., Perera, B. M. A. O. 2006. Improving artificial insemination services for dairy cattle in Ethiopia. In improving the reproductive management of smallholder dairy cattle and the effectiveness of artificial insemination services in Africa using an integrated approach. International Atomic Energy Agency (IAEA). Pp. 17-19. 